EPOS, XIII (1997), págs. 135-149

\title{
INTERTEXTUALIDAD E INTERPRETACIÓN DEL DISCURSO
}

\author{
Marta JOSE LuZÓN MARCo \\ Universidad Jaume I de Castellon
}

\section{RESUMEN}

Cada texto es inherentemente intertextual, lo que implica que su creación está determinada por textos previos (o pre-textos) y que debe ser interpretado teniendo en cuenta estos textos. El concepto de intertextualidad es básico para explicar el proceso de producción de un texto, pero también para comprender cómo un texto puede ser interpretado. Este artículo explora la intertextualidad en relación con los aspectos sociales y cognitivos de los procesos de producción e interpretación, $y$ analiza las referencias intertextuales de los textos desde el conocimiento previo del lector que le lleva a una interpretación coherente. La interpretación que cada lector hace de un texto depende en gran manera de cómo percibe la intertextualidad de ese texto. Dado que la intertextualidad se refleja tanto en la inclusión en un texto de un fragmento de un pretexto como en la incorporación de convenciones de otros tipos de textos, la discusión se basa en los conceptos de intertextualidad manifiesta e interdiscursividad.

\section{INTRODUCCIÓN}

Desde el Análisis Crítico del Discurso se considera la práctica discursiva como una actividad social, como un proceso de interacción social. Según Fairclough (1989: 24) «este proceso incluye, además del texto, el proceso de 
producción, del que el texto es un producto, y el proceso de interpretación, para el que el texto es un recurso» (mi propio énfasis). Así pues, dos conceptos claves en el análisis del discurso son los de producción e interpretación del texto. Tanto la producción como la interpretación son procesos so- ciales, dado que se basan en que los miembros de una comunidad comparten una serie de conceptos y convenciones. Estos procesos dependen del conocimiento previo que los participantes poseen y activan para producir e interpretar textos (ej. representaciones del mundo, valores, creencias, conocimiento de normas y convenciones sociales).

Para examinar la interacción entre el proceso de producción y el proceso de interpretación, en este artículo estudiaremos el concepto de intertextualidad desde la perspectiva del receptor que busca una interpretación coherente del texto. El objetivo del artículo es analizar los diferentes modos en que un texto incorpora otros textos (o pre-textos) y examinar cómo el receptor interpreta la relación entre los diferentes elementos del texto. En primer lugar, revisaremos brevemente los conceptos de intertextualidad y coherencia.

\section{INTERTEXTUALIDAD Y COHERENCIA}

Un texto no es un elemento autónomo, sino que está constituido por elementos de otros textos que están más o menos demarcados (Bakhtin, 1981; Kristeva, 1986). Es decir, los textos son inherentemente intertextuales: incorporan elementos de otros textos con un propósito específico. Todo texto está conectado a un universo de textos que le preceden y que le siguen (Grivel, 1982). Fairclough (1992) adopta la distinción usada por los analistas del discurso franceses (ej. Maingueneau, 1987) entre dos tipos de intertextualidad: intertextualidad manifiesta e interdiscursividad o intertextualidad constitutiva. La intertextualidad manifiesta es la propiedad de aquellos textos que abiertamente y explícitamente se construyen con elementos o fragmentos de otros textos específicos (Fairclough, 1992: 85), es decir, hay otros textos explícitamente presentes en el texto (ej. el discurso directo o el discurso indirecto). La interdiscursividad consiste en que un texto se construye incluyendo convenciones o elementos de otros tipos de texto (otros géneros, registros, estilos). ${ }^{1}$ Un ejemplo de este tipo de intertextualidad es la incorporación de convenciones propias del discurso científico en el discurso de la publicidad.

1 Otros autores que han explorado el concepto de intertextualidad establecen distinciones similares (Dewitt, 1991; Lemke, 1985). 
El modo en que los pre-textos se incorporan en un nuevo texto es complejo. Un texto puede mezclar varios pre-textos, asimilar el pre-texto, comentarlo, sustituirlo, resumirlo, contradecirlo, responder a lo que en él se dice, reacentuarlo (ej. usándolo de un modo irónico, parodiándolo) (Bakhtin, 1981; Fairclough, 1989; Heath, 1972). Es decir, los pre-textos pueden ser reestructurados para construir un nuevo texto, para modificar e innovar los tipos de discurso existentes o para generar nuevos tipos de discurso. Como Plett (1991: 17) afirma, «cada texto (...) existe como una interacción perenne entre identidad y diferencia. Esto constituye su intertextualidad».

El receptor de un texto debe ser capaz de descubrir la red intertextual del texto para interpretarlo, para conseguir una interpretación coherente. Partimos de la idea de que un texto no es coherente per se. Es el lector/ oyente el que confiere coherencia a un texto. Ello implica dos tipos de operaciones (Fairclough, 1989: 78): establecer relaciones entre las partes de un texto; y, establecer una conexión entre el texto y la propia experiencia del mundo, incluyendo la experiencia de textos previos, lo que conlleva determinar qué concepción del mundo presupone el texto. Así pues, para hallar coherencia en un texto el receptor debe establecer una conexión entre el texto y los esquemas que hay en su mente. Fowler $(1991: 43,60)$ define los esquemas como representaciones de conocimiento previo, compartidas por los miembros de una comunidad, que nos permiten comprender el mundo exterior y percibir la coherencia de nuestras experiencias. Los participantes en una interaccion deben compartir no sólo un conocimiento del mundo, sino también un conocimiento del lenguaje y de las convenciones que regulan el uso del lenguaje. Así pues, en la mente de los participantes existen diferentes tipos de esquemas (Carrell, 1983; Cook, 1994; Fairclough, 1989) que deben ser activados para interpretar un texto.

Al usar referencias intertextuales el productor del texto asume que el significado de estas referencias puede ser descubierto por un lector que posee determinados esquemas y que es, por tanto, capaz de encontrar la relevancia del texto. Para interpretar un texto el receptor tiene que tratar de unir los diferentes elementos del texto en un todo coherente. Es en este proceso de búsqueda de coherencia donde la experiencia previa juega un papel importante. Interpretar un texto implica percibir las conexiones existentes entre los esquemas que subyacen en el texto, incluyendo los esquemas evocados por las referencias intertextuales. Fairclough (1992: 135) sostiene que los textos construyen posiciones interpretativas, van dirigidos a un intérprete o lector ideal que es capaz de usar su experiencia previa para relacionar los diferentes elementos intertextuales de un texto y generar interpretaciones coherentes. Por ejemplo, un anuncio construye la posición intepretativa del consumidor, desde la cual el sujeto 
puede percibir la coherencia de este tipo de texto. Al incorporar determinados elementos intertextuales en un texto el autor construye una posición para el sujeto que interpretará el texto. Por tanto, el concepto de intertextualidad es básico para comprender cómo un sujeto percibe la coherencia de un texto.

La importancia de una perspectiva intertextual del concepto de coherencia ha sido enfatizada por distintos autores. Según Fairclough (1992: 81), esta perspectiva muestra que la interpretación no está solamente determinada por el texto, ni tan siquiera por los pre-textos que lo constituyen, sino también por todos los textos a los que un intérprete recurre en el proceso de la interpretación. Del mismo modo, Cook (1994: 171) señala que los significados intertextuales que se pueden derivar de un texto se deben describir para un lector o un grupo de lectores específicos. Diferentes lectores serán capaces de percibir más o menos referencias intertextuales, por lo que pueden interpretar el texto de forma diferente.

Tras revisar las nociones de intertextualidad y coherencia mostraremos con diversos ejemplos como el lector percibe el significado de la intertextualidad e interdiscursividad en un texto para conseguir una interpretación coherente.

\section{INTERPRETACIÓN DE LAS REFERENCLAS INTERTEXTUALES E INTERDISCURSIVAS}

Como ya hemos dicho, para interpretar un texto el lector necesita un conocimiento previo que se refiere a diversos aspectos: los codigos lingüísticos, el uso del lenguaje en relación con distintas prácticas sociales, la situación social en la que el acto discursivo se produce, el mundo exterior (Fairclough, 1989: 33; Winograd, 1982: 14). Parte del conocimiento que se usa en el proceso de interpretación es el contexto intertextual ${ }^{2}$ del texto. El intérprete debe descubrir a qué tipo de texto pertenece un texto específico, qué otros textos lo constituyen, y cuál es el significado y función que estos textos constituyentes tienen en el texto actual. Es decir, la interpretación de la intertextualidad consiste en dos fases: percepción del pre-texto, e integración del pre-texto en el significado global del texto.

La intertextualidad de un texto requiere que éste se interprete teniendo en cuenta textos previos, o convenciones textuales pertenecientes a otros tipos de textos. Por lo tanto el nuevo texto incluye al menos dos niveles de significado:

2 El termino contexto intertextual se ha usado en estudios sobre intertextualidad para referirse a el conjunto de textos previos que están relacionados con el texto actual. 
el literal, y el que deriva de su relación con el pre-texto que incorpora. El productor de un texto usa los fragmentos de otros textos o convenciones de otros tipos de textos con una intención determinada. Si el receptor no percibe la intertextualidad o interdiscursividad del texto parte del significado se pierde, ya que no se logra el objetivo de establecer una relación entre el texto actual y el pre-texto.

\subsection{Referencias intertextuales}

Un texto puede ser incorporado en otro de distintos modos, que dependerán del objetivo y significado del nuevo texto. Para determinar la función del fragmento de pre-texto incorporado es necesario analizar cómo este fragmento es contextualizado en el nuevo texto.

En algunos casos resulta imposible separar el pre-texto del texto actual, ya que el pre-texto ha sido transformado para construir un nuevo texto. La transformación de un texto conocido por el receptor produce un nuevo significado. Sin embargo, el nuevo significado depende en parte del reconocimiento por el lector de la referencia intertextual. El siguiente ejemplo es un anuncio del vino Los Molinos, que se ha construido transformando la expresión «Al pan pan y al vino vino».

(1) Al pan pan y al vino Los Molinos.

(Mia, 25/11 al 1/12, 1996)

La expresión «al pan pan y al vino vino» significa «claramente, sin tapujos» $y$ aparece frecuentemente precedida del verbo llamar: «llamar al pan pan y al vino vino». Al leer el slogan «al pan pan y al vino Los Molinos» el lector activa su conocimiento del significado de la frase hecha para interpretar el mensaje del productor: cuando se trata de vino Los Molinos es la única elección.

Otro ejemplo de transformación lo constituye el siguiente texto, que aparece en el encabezamiento de un artículo sobre la aspirina.

(2) Advertencia:

Este reportaje es sobre un medicamento.

Léalo con atención y en caso de duda... consulte a su médico o farmacéutico

(El semanal, 2/3/ 1997)

El receptor puede percibir claramente que este texto ha sido construido a partir de un texto previo que aparece en los anuncios de medicamentos. 
Advertencia:

Este anuncio es de un medicamento.

Lea detenidamente las instrucciones de uso y en caso de duda... consulte con su farmacéutico

$\mathrm{El}$ reconocimiento de la referencia intertextual hace que el lector no interprete el texto como una advertencia real, sino como un aviso de que la información del reportaje puede ser útil o interesante.

En estos casos la intertextualidad de un texto se logra alterando un pretexto o segmento de pre-texto. En realidad el pre-texto se reconstruye y se le da un nuevo significado. El resultado de esta transformación es lo que Plett (1991) llama «desviación intertextual». La transformación de un segmento de pre-texto para incluirlo en otro texto puede ser de varios tipos: adicion, sustracción, sustitución, permutación, y repetición (Plett, 1991). Estas operaciones se reflejan en los ejemplos anteriores. En el ejemplo (1) «vino» ha sido substituido por «Los Molinos». En el ejemplo (2) «anuncio» ha sido substituido por «reportaje», «de» por «sobre», «detenidamente» por «con atencion», «las instrucciones de uso» por «lo», y «su médico» ha sido sustraído.

Una operación frecuente es la adición, mediante la cual un nuevo texto se construye a partir de la expansión de un pre-texto. En el siguiente ejemplo el autor indica la intertextualidad utilizando letra negrita para marcar el texto que ha sido expandido.

(3) Hemos conseguido averiguar por qué algunos de ustedes No comparten la idea de incorporar una red informática a su negocio. Algunos creen que es demasiado caro. Otros que su negocio no es lo suficientemente grande. Creemos que le podemos ayudar a aclarar sus ideas y a aprovechar las ventajas de estar conectado al mundo en red. Con nuestros colaboradores comerciales daremos respuesta a sus necesidades $y$, como cada negocio es diferente, le ofrecerán las soluciones a medida que usted precise (...). Nuestros colaboradores comerciales han desarrollado soluciones para resolver más de 35.000 necesidades empresariales en todo el mundo, que nos sirven para no partir de cero, sino de situaciones que ya estén resultas, probadas y funcionando a pleno rendimiento. Sobre esta base, podemos crear soluciones diseñadas específicamente para adaptarse a su trabajo, reduciendo visiblemente su coste y el tiempo empleado. $Y$ esto es algo que siempre ha de tener en cuenta en su empresa.

$(A B C, 15 / 9 / 96)$

En este caso el pre-texto mantiene su forma original, pero sus elementos linguísticos forman simultáneamente parte del otro texto. El texto más extenso 
ha sido construido partiendo de un pre-texto («No le daremos soluciones que no estén diseñadas para su empresa»), incorporando todas las palabras del pretexto, de modo que los dos textos co-existen con su propio significado autónomo en el mismo espacio. Para entender el porqué de la intertextualidad el lector trata de establecer una relación entre los dos textos. El texto en negrita podría considerarse el resumen del texto que lo incluye o el mensaje principal. Incorporarlo de este modo hace que el lector le preste más atención, ya que debe emplear cierto esfuerzo de procesamiento para descubrir el sentido de la intertextualidad.

En otros casos hay un límite claro entre las referencias intertextuales y el resto del texto, de modo que la intertextualidad se señala explícitamente, con mecanismos tales como verbos de habla (decir, sugerir, etc.). Tradicionalmente se ha hecho una distinción entre representación del discurso directa e indirecta. En la representación directa las formas lingüísticas son las usadas en el texto original; en la representación indirecta las formas linguísticas se modifican para integrarse en el discurso del productor del nuevo texto.

Los siguientes ejemplos corresponden al artículo sobre la aspirina mencionado anteriormente. El texto describe la aspirina como algo que forma parte de nuestra cultura y las referencias intertextuales son usadas para reforzar esta idea. La intertextualidad se señala por medio de las comillas y de la inclusión de la referencia bibliografica.

(4) «Luego me quedé sentado en la silla y él (Bernardo) desapareció y volvió con una taza de te y una aspirina» Carmen Martín Gaite. Ritmo lento. Brugera, Barcelona, 1984.

«Se puso en pie, apagó el aparato y fue a la cocina a freírse otro par de huevos y a tomarse una aspirina». Rosa Montero. Amado Amo. Editorial Debate, Madrid, 1988.

(El semanal, 2/3/ 1997)

La representación de un discurso previo sirve con frecuencia para incorporar el testimonio de otras personas, como sucede en el siguiente ejemplo, donde anuncia un reloj Rolex:

(5) Un Rolex hace algo más que medir el tiempo.

Mientras usted lee este anuncio alguien en algún lugar del mundo está aventurándose hacia lo desconocido. El equipo elegido para acompañarle en su aventura habrá sido seleccionado con extremo cuidado. Su confianza en él deberá ser total. Con todo hay muchas posibilidades de que una de las piezas más vitales del equipo la lleve en la muñeca. Un Rolex Oyster. La innegable capacidad de un 
Rolex para seguir funcionando bajo las más severas condiciones es ya legendaria (...)

«Mi Rolex ha funcionado siempre sin un solo fallo. Sé que, como último recurso, lo puedo utilizar junto con la brújula solar para calcular el tiempo de estima» Tom Sheppard.

"Cuando te sumerges a 125 pies de profundidad, el reloj que te acompaña debe merecer toda tu confianza» Dra. Silva Earle.

«En el Artico, un reloj es el equipo básico de supervivencia» Janusz Kurbiel.

Y usted ¿a qué lugar del mundo va a llevar el suyo?.

(MUY Interesante, Enero,1995, n. 164)

El anuncio tiene dos partes. La primera es una descripción de una situación que permite presentar una característica del producto: su calidad. La segunda parte consiste en una representación directa de segmentos de tres discursos. Con esta segunda parte el texto incorpora los comentarios de clientes satisfechos, que sirven para confirmar lo que se dice sobre el reloj en la primera parte. Estos comentarios proporcionan un testimonio de la «innegable capacidad de un Rolex para seguir funcionando bajo las más severas condiciones».

Para que el texto consiga el objetivo persuasivo para el que ha sido diseñado el lector debe posicionarse de modo que el texto sea relevante para él. El texto es relevante para el lector si éste se identifica con las personas que dan el testimonio. El texto sugiere que los poseedores de un Rolex son un grupo limitado que ante todo exigen calidad. La presuposición existencial ${ }^{3}$ activada por el pronombre posesivo «el suyo» en la última oración ( $\ll Y$ usted $\iota^{a}$ que lugar del mundo va a llevar el suyo?») hace que el lector se sienta halagado, ya que se le considera una de estas personas que «necesitan» un Rolex. El anuncio no se presenta como una invitación a comprar un reloj, sino como una descripción de las personas que poseen un Rolex, entre las que el lector se puede encontrar.

También se recurre a la intertextualidad manifiesta cuando el autor desea incorporar un pre-texto para contradecirlo, para rechazar lo que en él se dice, como muestra el siguiente ejemplo, que es parte de una carta al editor.

(6) En la sección Música del 2 de febrero se dice que «David Bowie no ha obtenido éxitos importantes de cara al gran público desde ha-

${ }^{3}$ Una presuposición existencial afirma la existencia de un referente. Por ejemplo en la oración «y usted, a qué lugar del mundo va a llevar el suyo?», la expresión «el suyo» presupone la posesión de un reloj por el lector. 
ce más de 15 años». En 1983 Let's Dance fue número uno en Estados Unidos y Gran Bretaña. China Girl fue el diez y el dos respectivamente. En 1984 Blue Jeans llego al ocho y al seis.

(El semanal, 16/2/1997)

En el ejemplo (6) el autor construye un texto incorporando parte de un pre-texto para rechazar la correspondiente negativa del pre-texto. El lector interpreta el texto del ejemplo (6) porque conoce el género de la carta al editor y sabe que el propósito es expresar la opinión sobre un texto previo. El lector sabe que el autor expresará su acuerdo o desacuerdo con alguna afirmación hecha en el texto previo y esto le ayuda a buscar una relación coherente entre las distintas partes del nuevo texto.

Otra forma de incorporar un pre-texto es la presuposición. Los siguientes ejemplos presuponen textos anteriores:

(7) No es sólo que el idioma sea machista -que si lo es- sino que la sociedad lo es y el idioma refleja en palabras nuestros conceptos y apreciaciones sobre la realidad. (Muy Interesante, 1996, $\mathrm{n}^{\mathrm{Q}}$ 178))

(8) A todos los fans de Blur nos han encantado el cambio tan radical que ha dado. Que no sea un disco comercial no quiere decir que sea una desilusión.

(El Semanal 9/3/1997)

El ejemplo (7) presupone un pre-texto en el que se afirma que el idioma es machista. El productor del nuevo texto responde a esta afirmación en el pretexto matizándola. El ejemplo (8) presupone un texto en el que se afirma que el nuevo disco ha desilusionado a los fans de Blur. Para interpretar el nuevo texto y comprender su función el lector debe ser capaz de percibir que constituye una respuesta a un texto anterior.

\subsection{Las referencias interdiscursivas}

Ser capaz de reconocer que un texto incorpora convenciones de diferentes tipos de textos, o que mezcla distintos registros, estilos o géneros, implica un conocimiento de cómo se usa el lenguaje en relación con distintas prácticas sociales. Un concepto útil para entender como operan las referencias interdiscursivas es el de orden del discurso (Fairclough, 1989: 28), constituido por las convenciones asociadas con instituciones y prácticas sociales. Entre los elementos que configuran órdenes del discurso están el género, el estilo, el regis- 
tro o el discurso (Fairclough, 1992), lo que permite hablar de conceptos como el género de la entrevista, el estilo hablado, el registro de las retransmisiones deportivas, o el discurso científico. El término discurso ha sido interpretado de diferentes maneras dependiendo de la corriente de Lingüística desde la que se define (cf. Pennycook, 1994). En el Análisis Crítico del Discurso «discurso» se define en relación con las instituciones sociales. Según Kress (1985: 6-7) discursos son formas de expresión «sistemáticamente organizadas que expresan los significados y valores de una institucion». El discurso de una institución define y delimita lo que es posible o imposible decir en relación con esta institución.

La interdiscursividad se puede manifestar en el uso de convenciones propias de otro tipo de discurso. Un caso frecuente de interdiscursividad es el uso de convenciones propias del discurso científico en el discurso de la publicidad. El discurso de la publicidad es un discurso estratégico cuyo objetivo es conseguir resultados, inducir al consumo de determinados productos. El uso del discurso científico contribuye a construir una imagen del producto y también del productor. El siguiente texto, que anuncia un remedio contra el acné, ilustra claramente este proceso de construcción:

(9) Acne? No, gracias.

Zeliderm actúa al mismo tiempo contra tres factores que intervienen en el proceso acnéico:

1. La secreción excesiva de sebo.

2. El taponamiento del canal folicular por queratización.

3. La colonización microbiana.

Tratamiento local sintomático del acné vulgar.

(MUY Interesante, 1996, n. 180)

La primera línea del texto («Acné? No, gracias») pertenece al discurso hablado, e incorpora las convenciones de la conversación. El resto del texto corresponde al discurso escrito, más concretamente al discurso científico. Las convenciones del discurso científico están presentes en este texto: se usan palabras técnicas y específicas (ej. acnéico, canal folicular), los procesos se realizan por medio de nominalizaciones y no de verbos (ej. secreción, taponamiento). Aunque el texto es un anuncio el registro es propio del discurso científico. El uso de este registro hace que el receptor del texto cree una imagen del productor como un experto que le ofrece una solución a sus problemas. Así pues, la coherencia no depende de que el lector entienda el contenido del discurso científico, sino del hecho de que el lector confiera significado al uso en sí del discurso científico. El receptor tiene un problema (el acné) y en el 
anuncio se le ofrece una solución (Zeliderm). $\mathrm{El}$ recurso al registro científico contribuye a que el lector considere que esta solución es fiable.

El recurso a un registro especializado es también usado en el siguiente anuncio. La expresión «libertad sin cargos» pertenece al registro legal, es propia del lenguaje jurídico.

(10) Libertad sin cargos.

Ahora puedes disfrutar del nuevo servicio prepago para telefonía móvil GSM: la Tarjeta MoviStar Activa. Con un crédito inicial del 10.000 Pta y con la posibilidad de consultar el saldo disponible y recargarla en cualquier momento. Preparada para que la utilices desde cualquier Movistar cuando lo necesites. Sin contratos. Sin cuotas. Sin facturas. Y con total libertad.

(El Semanal 2/3/1997)

Al posible cliente se le ofrece «libertad sin cargos». Para encontrar la relevancia que el texto tiene para él, el lector debe reinterpretar la expresión «libertad sin cargos» y darle un significado diferente del que tiene en el registro legal. La relevancia de la expresión «libertad sin cargos» en el texto se descubre más tarde, cuando se explica cuál es el significado de «libertad» y cuál es el significado de «cargos». Al seguir leyendo el anuncio el lector averigua que los «cargos» son «contratos», «cuotas» o «facturas». Para tener significado en el texto la expresión fija «libertad sin cargos» debe ser analizada en cada uno de sus partes. Sin embargo, el nuevo significado incluye la connotación de «liberación» que la expresión tiene en el discurso jurídico. El productor del texto hace un uso estratégico de la interdiscursividad, utilizando los significados potenciales de una expresión para implicar determinadas connotaciones.

Con frecuencia la interdiscursividad consiste en mezclar convenciones de distintos géneros. Un género es una actividad comunicativa convencionalizada, con un proposito determinado, que está asociada con un tipo específico de actividad social. Cada género tiene una estructura retórica propia y requiere unos participantes determinados. Como Fairclough (1992: 126) hace notar, un género no es simplemente un tipo de texto específico, sino que implica un modo específico de producción, distribución y consumo del texto.

En los siguientes ejemplos el género del anuncio incorpora convenciones de otros géneros. En estos casos las convenciones que se incorporan se refieren a la estructura formal o a la expresión lingüística, pero no al proceso completo de producción, distribución y consumo que el género implica. Esto se puede ver claramente en el siguiente ejemplo, donde se adoptan convenciones del diario. 
(11) Domingo. No tengo ojos suficientes para verlo todo. A cada instante, en cada lugar, nace una emoción. Miércoles. He hecho una jugada maestra regateando en el zoco, en un puesto de especias. Jueves. Reencuentro con un couscous divino. Me he convertido en su más fiel seguidor. Sábado. En un bar de la Mamounia he comprendido por qué Churchill eligió este lugar para vivir su retiro.

(Muy Interesante, 1995, n. 169)

Las convenciones del género del diario son fácilmente reconocibles: uso de la primer persona, lenguaje subjetivo. Sin embargo, desde el punto de vista de la producción el diario es un producto individual, mientras que el texto del ejemplo (11), que utiliza las convenciones discursivas del diario, es un producto colectivo.

En el texto se crea una posición interpretativa para un sujeto lector que desea irse de vacaciones. El recurso es el mismo que se utiliza en el ejemplo (5). Se crea un lector que tiene los mismos intereses que el supuesto escritor del diario. El género usado es el diario porque es el más apropiado para plasmar las vivencias del sujeto y permite describir Marruecos desde el punto de vista personal que le interesa al sujeto lector.

Un caso similar de interdiscursividad lo constituye el siguiente ejemplo, donde se anuncia un producto de belleza utilizando el discurso propio de la interacción cara a cara.

(12) P:¿Existe algún remedio para las lineas de expresion?

$\mathrm{R}: \mathrm{Si}$, si de lo que se trata es de atenuar su aspecto.

P: ¿Debo creérmelo?

R: ¿Le ha mentido Clinique alguna vez?

P: ¿En que consiste este producto?

R: Es una crema muy emoliente que ayuda a la piel a construir y retener su propia hidratacion. Proporciona comodidad a las pieles muy secas a corto y largo plazo y les ayuda a protegerse de las agresiones medioambientales.

P: ¿Cómo se llama?

R: Moisture On-Line. Utilizando la llamada «tecnología mnemotécnica» reprograma la piel muy seca para que produzca una barrera de hidratación más fuerte y protectora. Está sometida a pruebas de alergia y es $100 \%$ sin perfume.

(El semanal, 16/2/ 1997)

El anuncio presenta el formato de la consulta a un especialista, basado en la estructura textual Pregunta-Respuesta. De este modo se anticipan y respon- 
den las preguntas que el posible cliente pueda tener. La relevancia del texto se consigue al construir un lector que se identifique con el que pregunta, porque tiene las mismas necesidades. El texto se basa en la suposición implícita (o creencia que se supone que el posible lector posee) (Fairclough, 1989: 202) de que las «líneas de expresión» están socialmente mal consideradas, y construye una posición interpretativa para los lectores que tienen este problema. La solución del problema debe proceder de alguien en el que el lector pueda confiar. Utilizando el género de la consulta, se intenta establecer una relación entre el lector y el productor similar a la existente entre un especialista y la persona que acude a él.

En muchas ocasiones se usan convenciones de un género distinto para sorprender al lector y crear una relación de complicidad entre el productor y el lector del texto. En el siguiente ejemplo un anuncio adopta las convenciones de una carta: fórmulas de encabezamiento y despedida, formulas de tratamiento, etc. La carta va dirigida al Sr. Daniel D., Montecarlo, Principado de Mónaco.

(13) Estimado Daniel D.:

Queremos expresarle nuestras más sinceras condolencias por su reciente separación. Es una lástima que, cuando decidió solazarse con aquella dama en una piscina, no recordase que DONDE LE LLEVE UN MITSUBISHI MONTERO NO LLEGA NADIE incluyendo los esforzados fot6grafos de la prensa con sus teleobjetivos.

Deseándole una próspera vida, nos despedimos atentamente.

(El semanal, 16/2/1997)

Un género del ámbito privado pasa a ser utilizado para la comunicación con el público. Los procesos de producción, distribución y consumo de este texto son distintos de los de una carta. Por ejemplo, este texto no va en realidad dirigido a la persona que figura en el encabezamiento (Daniel D.), sino a los lectores de la revista donde el anuncio se inserta. Así pues, el texto sólo adopta las convenciones formales de la carta. El lector será capaz de comprender la ironía del anuncio si conoce la situación a la que el texto hace referencia: la infidelidad de Daniel D., el marido de la princesa de Mónaco, fue captada por las cámaras de los fotógrafos, lo que les llevó a la separación. El contenido de la carta sirve a los productores del texto como un contexto perfecto para introducir su slogan «Donde le lleve un Mitsubishi Montero no llega nadie».

El ejemplo (14) sirve para anunciar una promoción del periódico Las Provincias. Se usa el género del diccionario en un espacio que corresponde a un 
anuncio. El término «picacor» ha sido inventado por el autor del texto para referirse a un pin que hace alusion a costumbres de la Comunidad Valenciana y que el periódico va a regalar. El texto se presenta como una definición de diccionario de siglos posteriores.

(14) Picacor (picacor). m. Dícese de aquello que causa punción en el corazon. Por extensión se aplica a todos los elementos y objetos que de una forma u otra son representativos de las cosas que afectan emocionalmente a la persona que los posee. También se aplican para designar a los objetos que recuerdan o hacen referencia a las raíces, caracteristicas o valores de una colectividad. Antiguamente, en especial en el mundo anglosajón y antes de sufrir las modificaciones que lo perfeccionaron, fue conocido como pin. (h) La primera documentación histórica que se encuentra relativa a esta voz corresponde a la última década del siglo XX y generalmente los investigadores lo asocian con el único periódico valenciano caracterizado por la defensa de los valores.

(Las Provincias, 16 de febrero de 1907)

Una definición se caracteriza por su objetividad, por presentar verdades generales o aceptadas. En el periódico se utiliza esta característica para dar el carácter de verdad aceptada a la afirmación «el único periódico valenciano caracterizado por la defensa de los valores».

\section{CONCLUSIONES}

Este artículo ilustra la importancia del concepto de intertextualidad para el análisis del discurso. Las referencias intertextuales revelan el proceso de producción de un texto, indicando los pre-textos que el productor incorpora en su construcción y los tipos de discurso con los que este texto está de una forma u otra relacionado. Los pre-textos se incorporan de formas distintas en el nuevo texto, de modo que la intertextualidad del nuevo texto puede ser más o menos explícita.

Por otra parte, la intertextualidad tiene un papel esencial en el proceso de interpretación del texto. Para llegar a una interpretación coherente de un texto el receptor debe examinarlo no como un elemento autónomo, sino desde una perspectiva intertextual. Interpretar un texto implica reconocer su conexión con otros textos y tipos de discursos y descubrir en qué modo los fragmentos de otros textos que se integran en él y las convenciones de otros tipos de discursos que incorpora contribuyen al significado global del texto. 


\section{BIBLIOGRAFIA}

BaKhtin, Mikhall (1981): The Dialogic Imagination, tr. C. Emerson y M. Holquist, Austin, University of Texas Press.

Bhatia, Vuay K. (1993): Analysing Genre: Language Use in Professional Settings, London, Longman.

DEWITT, AMY J. (1991): «Intertextuality in tax accounting: generic, referential and functional» en C. Bazerman y J. Paradis (eds.):Textual Dynamics of the Professions: Historical and Contemporary Studies of Writing in Professional Communities, The University of Wisconsin Press, pp. 336-357.

Fairclough, Norman (1989): Language and Power, London and New York, Longman.

FairClough, Norman (1992): Discourse and Social Change, Cambridge, Polity.

FOWLER, ROGER (1991): Language in the News, London, Routledge.

Grivel, ChaRles (1982): «Thèses preparatoires sur les intertextes» en R. Lachman (ed.): Dialogizität, München, Fink, pp. 237-248.

Heatr, Stephen (1972): The Nouveau Roman: A Study of the Practice of Writing, London, Elek Books.

KRess, GUNTHER (1985): Linguistic Processes and Sociocultural Practice, Victoria, Deakin University Press.

KRISTEVA, JULIA (1986): «The system and the speaking subject» en T. Moi (ed.): The Kristeva Reader, Oxford, Basil Blackwell, pp. 24-33.

LEMKE, JAY L. (1985): «Ideology, intertextuality, and the notion of register» en J.D. Benson and W.S. Greaves (eds.): Systemic Perspectives on Discourse, Vol. 1, Norwood, N.J. Ablex Publishing Corporation.

Maingueneau, D. (1987): Nouvelles Tendances en Analyse du Discours, Paris, Hachette.

PenNYCOOK, AlastaIR (1994): «Incommesurables discourses?» Applied Linguistics, 15/2: 115-138.

Plett, HeINRICH (1991): «Intertextualities» en H. Plett (ed.): Intertextuality, Berlin, Walter de Gruyter.

WINOGRAD, T. (1982): Language as a Cognitive Process. Vol. 1, London, Addison Wesley. 